\title{
Preliminary Study of Global Warming Mitigation by Grazing OTEC
}

Nai-Kuang Liang

Institute of Oceanography, National Taiwan University, Roosevelt Rd, Da'an District, Taipei City, 10617, Taiwan

Abstract

Global warming means the observed century-scale rise in the average temperature of the Earth's climate Received: September 20, 2017 system. However, most of the increased heat is stored in the ocean. This causes the sea surface temperature Accepted: November 15, 2017 to rise, producing extreme weather. Ocean Thermal Energy Conversion (OTEC) utilizes the temperature Published: November 17, 2017 difference between the sea surface water and deep seawater to generate electricity. OTEC requires pumping a large amount of deep seawater, which is clean, cold and rich in nutrients. If the used OTEC seawater, i.e. a mixture of warm and cold seawater, is released to the sea surface, an artificial upwelling is then created. The natural upwelling regions result in high levels of primary productivity and thus fishery production. The upwelling area will also present low sea surface temperature. Hence, large enough artificial upwelling may mitigate global warming. This process takes advantage of ocean thermal energy to generate clean energy, to create fishery grounds and improve climate change. An interdisciplinary research program promoted by the

\section{Keywords:}

Global warming Exergy, Seawater, Flowrate, Coastal waters UN will be necessary to achieve this goal.

\section{Introduction}

Global warming induces the global change, resulting in sea level rise and extreme climate.Thermal energy is much denser than the kinetic energy. One kilogram of seawater rising 1 degree Celsius reserves about 4000 joule. However, one kilogram of seawater moving 1 meter per second contains only 0.5 joule and the seawater density is 800 times larger than that of air. This is why typhoons become stronger, as the sea surface temperature increases by only 0.5 degree Celsius. Since 1979 ocean temperatures have increased by $0.13^{\circ} \mathrm{C}$ per decade [1].

In order to reduce fossil fuels, the renewable energy has been paid attention. Ocean Thermal Energy Conversion (OTEC) utilizes the temperature difference between the sea surface water and deep seawater to generate electricity. About 3 cubic meters per second (cms) flowrate of warm seawater and $2 \mathrm{cms}$ flowrate of cold seawater can produce $1 \mathrm{MW}$ power. Nowadays two land-based OTEC pilot power plants still exist, one in Okinawa and another in Hawaii. The land-based plant size is limited due to the cold water pipe, because the maximum pipe diameter for land-based OTEC plant is about 3 meters at present. Another type OTEC plant is floating, which is moored and the power is transmitted to shore. The floating plant should be located within a distance from shore, because a long power transmission cable results to much power loss. The floating plant has another problem, i. e., typhoon or hurricane.Therefore, sites for both land-based and floating OTEC plants are not so many as we expect. However, an OTEC plant ship may cruise in the tropical sea where water depth is larger than 1000 meter. The electricity power is not transmitted to shore, but can electrolysis water to produce hydrogen and oxygen. This is the grazing OTEC. In 1994 Avery and Wu advocated that ten 160 MW OTEC plant ships producing methanol or ammonia in USA are profitable [2]. The grazing OTEC size can be large enough to change electricity to hydrogen economically. However for ocean renewable energies, such as offshore wind, wave and current power, it is not economical to convert electricity into hydrogen.

\section{Upwelling}

In Ocean, the seawater temperature decreases as depth increasing. On the contrary, nutrients, i.e. nitrate, phosphate and silicate, which are essential to phytoplankton growth. It is a well-known fact that the natural upwelling area in the ocean is generally a high productivity area [3-5]. The nutrient in the photosynthesis zone, i.e. surface layer, is raised and the surface sea water temperature is decreased. The good fish catch is distributed in coastal waters, because coastal waters receive nutrients from the land. High productivity upwelling areas and coastal waters, in contrast to the low productivity of the open sea, is not due only to greater mineral enrichment. In upwelling areas the phytoplankton at the bottom of the food chain are usually aggregates of colonial diatoms that are large enough to feed fish of exploitable size. As a result the food chain is very short, with an average of 1.5 steps. The food chain in coastal waters is longer, averaging 3.5 steps. In the open sea, where phytoplankton at the bottom of the chain are widely scattered, single-celled diatoms, five steps are needed to produce exploitable fish and the energy transfer at each step is low in efficiency. The length of the chain was calculated by J.H. Ryther of the Woods Oceanographic Institution [6].

The major natural upwelling is due to wind-driven currents, which are diverted to the right of the winds in the Northern Hemisphere and to the left in the Southern Hemisphere due to the Coriolis Effect [7]. The result is a net movement of surface water at right angles to the direction of the wind, known as the Ekman transport. When Ekman transport is occurring away from the coast, surface waters moving away are replaced by deeper, colder and denser water. Normally, this upwelling process occurs at a rate of about 5-10 meters per day $[8,9]$. Such upwelling areas are along coasts, such as the Peru upwelling. The deep seawater is upwelled from the continental shelf boundary, of which the water depth is about 250 meters.

\section{Surface discharge of cold and warm seawater mixture}

A mixture of warm and cold seawater, is released to the sea surface, an artificial upwelling is then created. In the OTEC process cold water not less than 850 meters deep is pumped up. Referring to the Oceanographic Data of the South China Sea [10], the ratio between the mean nutrient concentrations, i.e. nitrate, phosphate and silicate, at $850 \mathrm{~m}$ and $250 \mathrm{~m}$ depth is about 7,89. The nutrients are negative

"Corresponding Author: Prof. Nai-Kuang Liang, Institute of Oceanography, National Taiwan University, Roosevelt Rd, Da'an District, Taipei City, 10617, Taiwan; E-mail: liangnk@ntu.edu.tw

Citation: Liang NK (2017) Preliminary Study of Global Warming Mitigation by Grazing OTEC. Int J Earth Environ Sci 2: 142. doi: https://doi.org/10.15344/2456351X/2017/142

Copyright: (c) 2017 Liang. This is an open-access article distributed under the terms of the Creative Commons Attribution License, which permits unrestricted use, distribution, and reproduction in any medium, provided the original author and source are credited. 
Citation: Liang NK (2017) Preliminary Study of Global Warming Mitigation by Grazing OTEC. Int J Earth Environ Sci 2: 141. doi: https://doi.org/10.15344/2456$351 X / 2017 / 142$

Page 2 of 3

in proportion to the seawater temperature. It is generally known that the cadmium concentration in the open ocean is closely related to biological activities, and that its distribution is similar to that of nitrate and phosphate [11]. The ratio between the mean nitrate, phosphate and cadmium concentrations at $800 \mathrm{~m}$ and $250 \mathrm{~m}$ depth for all data is about 8, 3 (Figure 1 and Figure 2). If we take an average upwelling speed as 7.5 meters per day, then a 100 MW OTEC plant ship can create 18 square kilometers of upwelling area. One hundred OTEC plant ships can then generate 1800 square kilometers of upwelling area and low temperature sea areas. This may mitigate global warming. Of course, any environmental impact, such as albino, algal toxicity etc., should be studied carefully.
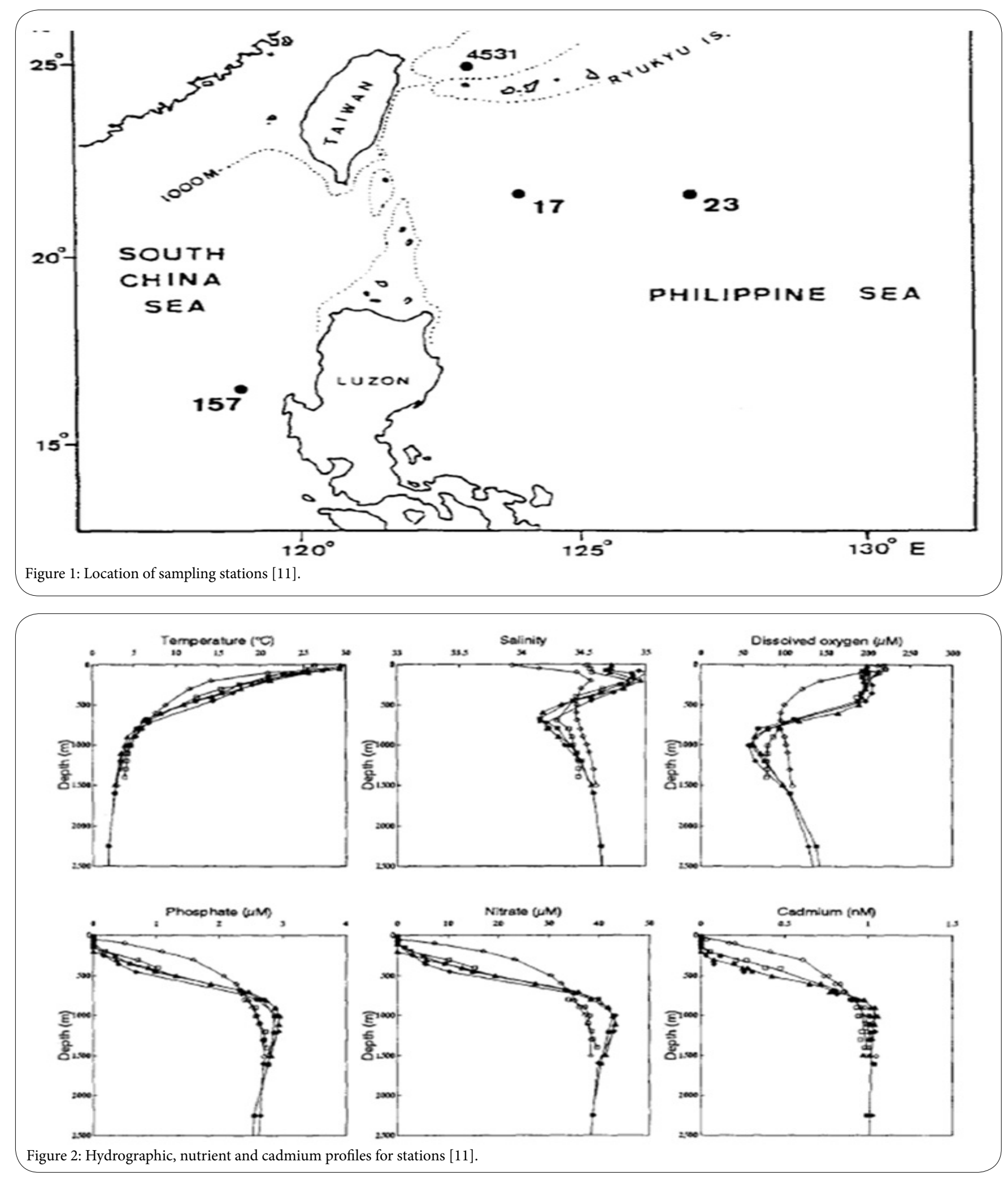


\section{Conclusions}

The grazing OTEC process may not only produce clean energy but also mitigate global warming and create new fishery grounds. This topic is comprised of various disciplines: engineering, oceanography, atmospheric sciences, economics, law of the sea, etc. The United Nations should promote the study of this interesting topic right now. The following research needs are urgent:

1. Hydrogen energy storage technology

2. What is the influence to the ocean circulation as large amount of cold and warm seawater mixture is discharged to the seasurface?

3. How large area of artificial upwelling can mitigate global warming?

4. How and how much cold and warm seawater mixture discharge can create a fishery ground? Is there any environmental impact?

\section{Competing Interests}

The author declare that he has no competing interests.

\section{References}

1. Trenberth KE, Jones PD, Ambenje P, Bojariu R, Easterling D, et al. (2007) Observations: Surface and Atmospheric Climate Change. In: Climate Change 2007: The Physical Science Basis. Contribution of Working Group I to the Fourth Assessment Report of the Intergovernmental Panel on Climate Change [Solomon, S., D. Qin, M. Manning, Z. Chen, M. Marquis K.B. Averyt, M. Tignor and H.L. Miller (eds.)]. Cambridge University Press, Cambridge, United Kingdom and New York, NY, USA

2. Avery $\mathrm{WH}, \mathrm{Wu} \mathrm{C}$ (1994) Renewable energy from the ocean- a guide to OTEC, New York: Oxford University Press

3. Liang NK, Hsieh CT, Huang PA, Li DJ, Chu LL, et al. (1978) Artificial upwelling induced by ocean currents--theory and experiment. Ocean Eng 5: 83-94.

4. Liang NK, Peng HK (2005) A study of air-lift artificial upwelling, Ocean Eng 32: 731-745.

5. Lin S, Chen J, Liang NK, Chen Y (2016) A study on wave-induced artificial upwelling. Mar TechnolSoc J 50: 48-55

6. Pinchot GB (1970) Marine farming. Scientific Am 223: 1521

7. Mann KH, Lazier JRN (2006) Dynamics of Marine Ecosystems: BiologicalPhysical Interactions in the Oceans. Oxford: Blackwell Publishing Ltd. ISBN 1-4051-1118-6

8. Anderson DM, Prell WL (1993) A 300 KYR record of upwelling off Oman during the late quaternary: evidence of the Asian southwest monsoon. Paleoceanography 8: 193-208.

9. Bakun A, Nelson CS (1991) The seasonal cycle of wind-stress curl in subtropical eastern boundary current regions. J Phys Oceanogr 21: 18151834.

10. Oceanographic Data of the South China Sea (1972) Special Publication: No. 2, Institute of Oceanography, National Taiwan University

11. Pai SC, Chen HY (1994) Vertical distribution of cadmium In marginal seas of the western Pacific Ocean. Mar Chem 47: 81-91 